\title{
A Administração cotidiana e a heterogeneidade da pobreza ${ }^{1}$
}

Peter Spink ${ }^{2}$

RESUMO: As discussões recentes sobre a pobreza têm revelado como tendência geral, a busca para abordagens mais interativas, considerando não somente as capacidades e os recursos individuais e sociais, mas também a provisão e o acesso aos serviços e bens necessários para uma vida digna, menos desigual e com exercício pleno da cidadania. Ter renda adequada para uma vida digna, ter acesso a conhecimentos, às ferramentas de trabalho e créditos necessários para assumir um papel na comunidade de cabeça erguida, passa por caminhos diferentes em lugares diferentes e como consequiência, torna-se quase impossível, a formulação adequada de políticas públicas e de ações governamentais nos moldes tradicionais. Trabalhando com experiências identificadas e analisadas pelo Programa Gestão Pública e Cidadania, apresentaremos as lições aprendidas no nível meso das ações publicas onde atores públicos, técnicos e agentes comunitários estão buscando soluções específicas nos limites de suas necessidades e territorialidades. O resultado é um realinhamento da política pública a partir do local entendido como lugar, e o reconhecimento das possibilidades de novas re-articulações dos processos de gestão intergovernamental partindo de matrizes interorganizacionais de médio alcance.

PALAVRAS CHAVE: Administração Pública: pobreza, governo local, cidadania, políticas públicas.

ABSTRACT: Recent discussions of poverty have shown the general tendency to adopt more interactive approaches that consider not only individual and social capacities and resources but also the supply and access to the services and goods necessary for a life that can be lived with dignity, less unequal and with a fuller exercise of citizenship. However, to be able to have adequate income, access to knowledge and skills, to the tools and financial credits necessary to assume a dignified role within a community are objectives that are built through different paths in different places and, in consequence, are very difficult to be specified in the more traditional "one size fits all" approach to policy making. Working with experiences identified and analyzed by the Public Management and Citizenship Program, this paper discusses some of the lessons learned at the mid-range of public action, where public agencies, specialists and community activists are seeking specific solutions within the limits of specific territorial arrangements. The result has been the realignment of public policy with an emphasis on the places of everyday action and the recognition of the importance of new articulations in intergovernmental management within a matrix of mid-range relationships.

KEY WORDS: Public Management, poverty, local government, citizenship, public policy.

\footnotetext{
${ }^{1}$ Texto apresentado no painel Pobreza, realidades locais e protagonismo social no : X Congresso Internacional del CLAD. Santiago, Chile 18-21 Outubro 2005.

${ }^{2}$ Professor Titular da Fundação Getulio Vargas de São Paulo e Coordenador do Centro de Administração Pública e Governo.
} 


\section{Introdução}

O Brasil se costuma dizer são muitos Brasis ao mesmo tempo; mas o Brasil que os governos e os partidos políticos não gostam que seja discutido no cenário internacional é o Brasil cujo perfil atual é bem resumido na seguinte frase: "A América Latina é talvez o continente mais desigual no mundo e o Brasil é o país mais desigual deste continente”. Esta frase é do Relatório Desigualdades na América Latina: rompendo com a história (Banco Mundial 2003).

Assim, podemos dizer que campeão em muitas esferas o Brasil é atualmente o vicecampeão da desigualdade. Em termos de distribuição de renda, os $10 \%$ mais ricos da população Brasileira concentram quase $50 \%$ de toda a renda do país; ficando os noventa por cento restantes com a outra metade. Na outra extremidade, os $10 \%$ mais pobres são donos de somente $1 \%$ da renda. Há entre nós, pelo menos 50 milhões ( $30 \%$ da população) de pessoas vivendo com renda familiar per capita de menos de 80 reais por mês (um dólar por dia); Somente $15 \%$ das famílias brasileiras tem uma renda familiar de mais de quatro mil reais (1,500 US\$) - suficiente para entrar no mercado de bens de consumo e interessar o capitalismo internacional.

A taxa de desemprego nas grandes cidades brasileiras como Porto Alegre, São Paulo, Belo Horizonte está atualmente variando entre $15 \%$ e $20 \%$ chegando até quase $30 \%$ em algumas cidades do Nordeste como Salvador. Entretanto estas porcentagens - mesmo sendo alarmantes - são médias, se as analisamos em relação ao gênero descobrimos que a taxa de desemprego das mulheres é maior do que dos homens ou em relação à etnia, os números demonstram que o nível de desemprego entre a população negra é maior do que entre a população branca. Aliás é necessário - até obrigatório - num país com tal grau de desigualdade como o Brasil, olhar com bastante suspeita qualquer estatística apresentada em termos de uma média populacional geral. Por exemplo, não há duvida que a mortalidade infantil para menores de cinco anos tem diminuído no país. Mas não podemos esquecer, que as crianças que nascem nas famílias mais ricas, têm de três a cinco vezes, mais possibilidade de sobrevivência nos seus primeiros cinco anos do que as crianças que nascem nas famílias mais pobres. 
A alfabetização é outro grande jogo de esconde-esconde, culpado por tudo e constantemente refém do jogo dos indicadores. Ou seja, o que adianta dizer que a taxa de analfabetismo tanto para homens quanto para mulheres já baixou para $13 \%$ quando a variação entre a zona urbana e a zona rural é de três vezes e a variação geral entre as regiões e de quatro vezes; ou seja, de $7 \%$ até $26 \%$ na média geral. Então, o que adianta falar em alfabetização sem lembrar os argumentos de Paulo Freire (2001) de que, aprender a ler e escrever, somente são necessários porque o acesso ao poder, às oportunidades e aos processos de transformação no nosso tipo de sociedade tornou tais competências essenciais.Enquanto que, não poder agir efetivamente num mundo de formulários e documentos é o dia a dia de $30 \%$ de brasileiros; vinte quatro porcento na zona urbana e cinqüenta e quatro porcento na zona rural. Em termos regionais estas porcentagens chegam até quase $90 \%$ em algumas áreas rurais; condições perfeitas para a atuação do trabalho escravo.

Poderíamos continuar com mais e mais estatísticas, sobre a segurança pública, sobre a habitação, mas prefiro terminar esta introdução com somente duas. A primeira foi retirada de um excelente estudo recente realizado pela Fase no Rio de Janeiro em 2003 sobre Novos Marcos para Relações Raciais. Utilizando os dados do censo e outras fontes eles recalcularam o IDH para três Brasis. O primeiro é o Brasil geral, o Brasil da média, que ocupa o septuagésimo nono lugar no mundo. O segundo é o Brasil branco, que ocupa o quadragésimo nono lugar e o terceiro é o Brasil negro que ocupa o centésimo oitavo lugar (quase sessenta lugares mais para baixo).

A segunda vem de nosso trabalho no programa Gestão Pública e Cidadania na Fundação Getulio Vargas de São Paulo, onde desde 1996 estamos trabalhando na identificação e disseminação de iniciativas de governos subnacionais brasileiros (estados, municípios e os governos próprios dos povos indígenas), que não somente melhoram os serviços públicos mas, geram um impacto positivo na construção da cidadania. Até hoje temos mais de oito mil experiências registradas oriundas de quase 900 municípios, além de estados e muitos dos povos originários. Ao analisar estas experiências, vemos que são provenientes de municípios de todos os tamanhos, de todas as partes do País; de partidos políticos os mais variados e sobre tópicos e questões que se colocam no dia a dia da vida local. Podemos falar de municípios onde entre $75 \%$ - 90\% da população está sendo atendida nos seus 
domicílios pelas equipes de saúde local; onde questões complicadas como violência contra a mulher, geração de emprego e renda, recuperação ambiental e muitas outras questões estão sendo trabalhados com bastante criatividade. Há trabalhos que interconectam gerações; outros que interconectam saberes e muitos que simplesmente conectam pessoas e começam a resolver os problemas do dia a dia.

A conclusão inicial portanto, têm dois lados: de um lado uma situação historicamente construída, descrita por um colega como sendo um desastre em câmara lenta; de outro, sinais de reação a partir da base da sociedade, especificamente do nível local e municipal, buscando agir dentro daquilo que é possível.

\section{Práticas Públicas e Pobreza}

Em outubro de 1998, o Programa Gestão Pública e Cidadania com o apoio da Fundação Ford realizou o primeiro de um ciclo de seminários voltados à análise e reflexão sobre estratégias locais para redução da pobreza. Em cada encontro de dois dias, por volta de 30 pessoas de diferentes universos de ação estiveram presentes para debater o espaço possível de ação local no enfrentamento da pobreza.Os encontros eram marcados pelas discussões de programas e políticas locais, desenvolvidas por governos municipais, estaduais, pelos povos indígenas e pela sociedade civil. A questão que orientava as discussões era simples e direta: "Há indícios de que há um espaço de ação de combate à pobreza entre as macropolíticas nacionais e as ações desenvolvidas a partir da sociedade civil?’.

As regras dos encontros eram igualitárias. Todos os participantes tinham a oportunidade de discutir e argumentar, havendo um equilíbrio satisfatório entre as apresentações acadêmicas, os relatos das experiências e as análises técnicas.As experiências discutidas e analisadas foram escolhidas a partir do banco de dados do Programa Gestão Publica e Cidadania e complementadas por outros casos identificados a partir de estudos sobre o papel de alianças entre organizações públicas, não-governamentais e privadas na redução da pobreza, desenvolvidos com o apoio do Banco Mundial (Camarotti \& Spink, 2000a, 2000b). Durante o debate, outras experiências e iniciativas foram mencionadas pelos participantes. 


\section{As discussões}

No inicio dos encontros, as falas de todos os participantes pareciam revelar uma leitura de que a situação que o país enfrenta é um produto, em parte, das abordagens simplistas sobre o fenômeno da pobreza, presente não somente em estudos, mas também no imaginário social, que buscam explicar o fenômeno, ora pela ausência de recursos materiais dos indivíduos - "pobre" é quem não tem dinheiro - ora, exclusivamente pelos efeitos da globalização e das políticas macroeconômicas, deixando em segundo plano os múltiplos mecanismos que produzem a desigualdade social e a exclusão e as ações administrativas que contribuem para a sua manutenção.

À medida que as discussões foram sendo ampliadas, ao longo das oficinas, houve uma tendência a buscar uma abordagem mais plural, focalizando não somente as capacidades e os recursos individuais ou sociais, e as estratégias de promoção do desenvolvimento econômico socialmente sustentável, mas também a provisão e o acesso aos serviços e bens necessários para uma qualidade de vida mais digna, menos desigual e caracterizada pelo exercício pleno da cidadania.

Observou-se, conseqüentemente, que para repensar os caminhos que levarão à redução da pobreza, é essencial entendê-la como uma questão de cidadania, de democratização da sociedade e de construção de novos padrões de sociabilidade. Sem uma atenção prioritária à temática da pobreza, assimilada a partir do enfoque da exclusão e da desigualdade social, a situação no país só tende a se agravar. Tornar políticas públicas, ações administrativas e programas especiais efetivamente sensíveis à questão exigirá - de acordo com as análises feitas durante os encontros - intervenções em níveis institucionais diversos e, também em distintas dimensões do processo de exclusão, por meio de novas configurações e relações entre os diferentes atores envolvidos: as instituições e representações do Estado nacional e subnacional, a sociedade civil e o meio empresarial. Enfim falar em pobreza é acima de tudo falar em falta de cidadania.

Nos discurso dos participantes das oficinas fica evidente a concepção de que qualquer governo nacional eleito democraticamente é responsável pelas conseqüências sociais de suas políticas e ações em qualquer área ou campo de atuação e, também pelo seu impacto nas condições de vida da população, nos direitos individuais e coletivos e no exercício 
pleno da cidadania. E que a questão social não pode ser reduzida a uma área específica de atuação governamental, mas deve ser considerada como permeando toda e qualquer ação, incluindo a econômica.

Podemos concluir que o enfrentamento da pobreza deve ser entendido como uma questão de construção de cidadania, de democracia, de empowerment, de emancipação, de dar voz e vez às populações em situação de pobreza. E que é necessário confrontar as relações paternalistas e clientelísticas. Neste sentido, é essencial que as organizações comunitárias sejam reconhecidas enquanto tais, sem maior preocupação com a sua profissionalização. Deve-se evitar, portanto, a criação de novos mecanismos que possam vir a substituir essas mesmas organizações a pretexto de maior eficiência.Qualquer tentativa de reduzir a desigualdade deve levar em consideração também que o acesso ao "bem-estar" é um jogo de soma zero face aos recursos e serviços implicados, como também em relação ao poder. É muito importante reconhecer que os interesses que se encontram mais bem representados normalmente se apropriam da parcela mais significativa dos bens e serviços, simplesmente por ser mais bem posicionado. A superação da desigualdade requer o enfrentamento e a efetiva redistribuição de poder, ampliando o espaço público para a incorporação de saberes diversos e às vezes conflitantes. A sustentabilidade das ações voltadas para o combate à pobreza se ancora na coesão social. A articulação política e social local é uma constante em muitas das experiências que conseguiram criar raízes.

As discussões foram marcadas por um sentimento de que o período atual se caracteriza como uma encruzilhada ética e moral, na qual o passivo social dos modelos de desenvolvimento pregressos e do ajuste estrutural atual é imenso, levando ao desgaste da própria noção de coesão social e civilização. Por outro lado, encontramos no âmbito local sinergias diversas que recuperam a noção do "compromisso social" e avançam na criação de um espaço público permitindo à sociedade civil uma volta à cena política. Nessa ótica, a definição do interesse público, não mais parece restrita a um conjunto limitado de atores, mas se amplia para incorporar a presença e as demandas de setores até então excluídos e permitir, desta forma, a possibilidade de um espaço público mais abrangente e inclusivo. Assim, a compreensão de que a pobreza e a exclusão social são conseqüências dos impactos de políticas públicas, de prioridades e de escolhas, as possibilidades de superação da pobreza também dependem de uma ação incisiva no campo das políticas públicas. 
Durante os debates, aprendemos algumas lições a partir da troca de experiências e da análise dos programas, ações e políticas locais de sucesso, que contrastavam com muito que é discutido na literatura de desenvolvimento; especialmente aquela parte influenciada pela linguagem de gestão de projeto, de metas, objetivos e de formulários padrão de ação, incluindo "best practices". As principais lições são identificadas a seguir.

\section{Lições aprendidas com as oficinas e as experiências}

Primeira: as iniciativas demonstram a potencialidade das ações locais e a presença de uma tecnologia social subjacente. Revelam toda a vitalidade e também a possibilidade de replicação tanto em termos de estratégias, quanto em termos de ação específica. A sua disseminação é importante, como também a sua efetiva avaliação. Por isso, há necessidade de se trabalhar com indicadores que possam ser utilizados para esta finalidade.

Segunda: há uma capacidade empreendedora presente nas experiências discutidas. Entretanto, as experiências também sinalizaram para a carência de ação governamental em diversos níveis. Torna-se necessário, portanto, criar políticas, regras e instrumentos mais flexíveis e também novos arranjos entre esferas de governo. Os exemplos são vários: falta de integração entre políticas públicas e atividades de geração de renda, impasses entre jurisdições subnacionais e impasses entre as ações locais e a política nacional. A impressão geral é que o desenvolvimento local se realiza apesar da política nacional e sem o seu suporte.

Terceira: as ações locais precisam de maior integração. A ausência dessa integração tem implicações diretas na sua sustentabilidade. No entanto, há uma distinção importante a ser feita entre a necessidade e o desejo de desenvolver ações intersetoriais e a dificuldade encontrada para criar formatos viáveis para a sua execução - em termos de políticas e desenhos organizacionais e gerenciais.

Quarta: os mecanismos de controle social continuam frágeis, embora exista uma participação ativa da população-alvo e das organizações da sociedade civil nos projetos contemplados. Essa participação é observada sob diferentes formas e aspectos e coloca em destaque a importância de aprofundar toda essa diversidade e opções de engajamento, o que 
leva a crer que o espaço público emergente é um espaço híbrido e não pode ser reduzido a uma série de conselhos consultivos.

Quinta: a territorialidade dos exemplos de ação eficazes também é um elemento importante a ser levado em consideração. É fundamental reconhecer a territorialidade enquanto alcance. Territorialidade não é sinônimo de Estado ou de Município e freqüentemente ela está relacionada aos espaços intermediários, de região intermunicipal ou de distrito intramunicipal. Territorialidade emerge também como um elemento significativo em termos identitários: o lugar, as raízes históricas e culturais.

Sexta: intersetorialidade e multissetorialidade são em geral resultados e não pontos de partida das ações eficazes de combate à pobreza. Nesse processo, à medida que as ações evoluem, aspectos diversos são contemplados a partir de uma visão sistêmica ou de um encadeamento de iniciativas que tentam conjugar melhoria de qualidade de vida, emancipação social e geração de atividades produtivas. Apesar da sinalização de bons resultados, promover ações intersetoriais e multissetoriais não é uma tarefa fácil, elas exigem novos arranjos institucionais, novas posturas e também novos valores políticos.

Sétima: a temática de emprego e renda está sempre presente na discussão sobre estratégias de combate à pobreza, seja em relação à promoção de atividades econômicas, seja em relação à sua inserção em outras atividades integradas como, por exemplo, a urbanização e o desenvolvimento rural. Ficou também evidente, a partir das análises e debates, a necessidade de deslocar a discussão sobre emprego e renda do estritamente econômico para o campo da ética e dos direitos.

Oitava: no tema de geração de emprego e renda observa-se ainda uma questão fundamental relativa à adequação entre oferta e demanda: a públicos específicos, oferta específica. Neste sentido, deve-se levar em conta toda uma pluralidade de instrumentos, modalidades de apoio, flexibilidade de metodologias e harmonia no enfoque. Trata-se aqui de buscar maior complementaridade entre a realidade, os saberes e as oportunidades que emanam da população-alvo.

Nona: além da flexibilidade, adequar oferta e demanda requer, sensibilidade às questões de gênero, que são em grande parte ignoradas. Na área específica do crédito, há uma dificuldade freqüentemente assinalada e que se refere ao próprio processo de exclusão - o 
que foi chamado por muitos de "bloqueios aos sem acesso". Os relatos das experiências também revelaram os impasses criados tanto no âmbito urbano quanto no âmbito rural, para os pequenos agrupamentos em fase de formação como também em relação aos acessos a linhas de financiamento para organizações já constituídas. O apoio ao acesso e à articulação junto aos mercados é vital para a sobrevivência das pessoas envolvidas nos projetos. A capacidade de identificar e avaliar os elementos-chave que compõem as cadeias produtivas (organização da produção, transferência de tecnologia, financiamento, capacitação, processamento da produção e comercialização) é um dos caminhos para intervenção, na medida em que torna mais visíveis os elementos de desigualdade e exclusão social. A economia solidária também oferece caminhos e precisa ser compreendida como confrontação com outros modelos econômicos e não como simples complementação.

Décima: programas de capacitação privilegiam em demasiado a formação técnica, considerada imprescindível para as oportunidades de trabalho, esquecendo a importância de igualmente privilegiar a construção de uma consciência cidadã e de se atribuir maior respeito ao conhecimento e às habilidades já existentes na população.

Décima primeira: faz-se também importante ampliar a temática de emprego e renda, e associá-la aos outros campos e áreas, incluindo as arenas interorganizacionais emergentes, como os consórcios intermunicipais. Porém, uma provável descentralização nas esferas de poder exigirá certamente mudanças na cultura política, superando-se a lógica clientelista que reproduz 'balcões e grupos cativos de 'pobres' atendidos por este ou aquele segmento da máquina governamental", como foi assinalado por um dos participantes dos nossos encontros.

Décima segunda: o caminho para a intersetorialidade parece ser o enfoque territorial, conduzindo os diversos elementos para dentro de um contexto onde o controle social é possível. O lugar é, portanto essencial, seja ele submunicipal, municipal ou supramunicipal. A criação de esferas públicas ampliadas nas quais emancipação e transferência de poder (empowerment) levam ao confronto e geram a conexão entre serviços, parece ser um bom caminho a ser privilegiado. Há um grande número de ações acontecendo de baixo para cima, em que pessoas estão conseguindo desenvolver atividades produtivas. Não obstante, falta uma atitude, uma ação no sentido oposto - de cima para baixo - desbloqueando os 
impasses que, ao não distribuir adequadamente as oportunidades, acabam por reproduzir, quando não produzir, a desigualdade e a exclusão social. Há necessidade urgente de assumir o desafio e aceitar o conflito da discriminação positiva.

Décima terceira: a questão da discriminação positiva, ou ação afirmativa torna-se mais visível quando se discute prioridades. Face ao imenso contingente de pessoas em situação de pobreza, em relações socioeconômicas de exclusão e desigualdade, qual deve ser a prioridade? Percebe-se que muitas iniciativas acabam não atingindo as pessoas que se encontram em situação de extrema precariedade. Nessa perspectiva, corre-se o risco de reproduzir processos de discriminação e exclusão dentro do próprio campo da ação para a redução da pobreza e para inclusão. Não é fácil decidir quem deve ser priorizado. Reconhecendo que toda política pública deve ser considerada de fato distributiva - no sentido de que não há neutralidade na política pública - resta, portanto, saber para quais setores a distribuição efetivamente se orienta. Assim, pergunta-se quem de fato é beneficiado pelas ações públicas e quem deve ser beneficiado.

Décima quarta: durante o processo de discussão sobre as diversas experiências apresentadas, tornou-se claro que, em resposta à questão levantada no início do processo: "há um espaço de ação de combate à pobreza entre as macropolíticas nacionais e as ações desenvolvidas a partir da sociedade civil?", a resposta foi positiva, há sim, um espaço para a ação subnacional. Entretanto, esta ação vem sendo construída na ausência de uma política pública nacional de redistribuição de renda, comprometida em combater efetivamente a pobreza.

Décima quinta: os diversos arranjos locais e subnacionais - sejam estes de estados, municípios, de agências regionais e locais do governo nacional, de alianças com organizações não governamentais e comunitárias, empresas e cooperativas e toda uma variedade de instituições e organizações cívicas nas quais a igreja católica continua demonstrando uma competência especifica e exemplar - têm muito a contribuir e mostram caminhos possíveis, construídos a partir de soluções simples e concretas. Porém, vale salientar que estes caminhos não podem ser considerados como substitutos de uma responsabilidade institucional maior, na qual o papel do Estado é central. 


\section{Consensos}

Este ciclo de debates permitiu a troca de experiências entre diferentes atores, o que possibilitou a realização de análises complexas acerca das iniciativas discutidas e das estratégias locais de superação da pobreza. Além disso, foi possível discutir o contexto onde as ações se desenvolvem e as dificuldades enfrentadas no cotidiano para transformar a realidade local. Durante os debates construímos alguns consensos que possibilitam uma mudança de perspectiva na análise da pobreza. O primeiro deles é o de que há um espaço de ação no âmbito local, que precisa ser urgentemente assumido e ocupado e que vem demonstrando sinais animadores da conquista de poder e de oportunidades, não se pode ignorar o contexto mais amplo dentro do qual o fenômeno de pobreza e exclusão se constrói: os dramas decorrentes da globalização, das políticas de ajuste estrutural, que não privilegiam o social. É urgente a adoção de políticas que garantam um mínimo social, sensível às questões de gênero, da infância e adolescência, viabilizadas por meio de abordagens simples, como programas de renda-mínima, salário social, bolsa-escola, que demonstram na prática a eficiência das soluções simples.

Assim, frente às possibilidades de agir para transformar a realidade, diversos são os temas a serem contemplados: a importância e a dificuldade de criar abordagens intersetoriais; a necessidade de políticas públicas que estimulem a co-responsabilidade e o protagonismo; a presença na política social da temática de trabalho e renda dentro da ótica de um mínimo social enquanto direito fundamental; a capacidade de efetivamente atingir os grupos mais vulneráveis; a importância de se dar maior visibilidade aos novos mecanismos interorganizacionais e o papel formador de ações sociais de controle do agir público.

Um outro aspecto que precisa ser repensado é a proliferação de conselhos e outras instâncias formais de decisão e consulta no âmbito de políticas públicas específicas. Reconhecer o potencial de complementaridade horizontal dos diversos colegiados pode levar ao fortalecimento do seu papel fiscalizador e orientador, enfrentando assim as tentativas da sua apropriação artificial por interesses hegemônicos de elites e grupos profissionais específicos. Há muitos exemplos de situações em que as informações e oportunidades não chegam onde deveriam, e em que as exigências de consulta acabam por virar barreiras em relação ao que buscam: o engajamento efetivo da comunidade. 
Houve um consenso em torno da centralidade de uma nova concepção do local visto como lugar, que não se traduz em nenhum nível específico de governo, mas sim um lugar onde a lógica da proximidade, do encontro e do confronto é possível. O lugar não é dado, mas se define e se redefine a partir das ações, remetendo a um contexto de relações que não é somente local. Requer dos agentes públicos uma prática pedagógica ética e cívica que evidencie a promoção da cidadania. Requer, também, instrumentos de avaliação que estimulem o debate e possam produzir conhecimentos. É preciso lembrar que as ações emergentes, reposicionam o papel do Estado, mas não reduzem o seu papel central no enfrentamento da pobreza percebida a partir da ótica da exclusão e da desigualdade social. As múltiplas organizações da sociedade civil, ao apresentarem soluções, dão sinais evidentes de uma responsabilidade social e de um engajamento cívico, porém não desobrigam, em nenhum momento, as organizações públicas de uma ação igualmente responsável e comprometida.

Podemos dizer ainda, que as soluções locais na área de emprego e renda são freqüentemente resultados de ações que favorecem o microcrédito e a capacitação, mas que são também frutos do diálogo e do apoio direto à população envolvida. Aprender a reconhecer e a respeitar os muitos saberes existentes e, também, levar em consideração a importância de uma solidariedade no quotidiano são elementos que criam condições para o êxito dos projetos voltados para redução da pobreza. Para atingir resultados concretos, observa-se ainda a necessidade de flexibilizar linhas de apoio e de ações técnicas; algo que infelizmente muitos dos programas e organismos públicos têm dificuldade em assumir. A lacuna que se cria, em conseqüência, é em si a expressão da permanente produção e reprodução da desigualdade e da exclusão social. Grosso modo, a máquina pública parece não estar ainda preparada, ou mesmo disposta, a encarar seriamente a necessidade de redução da pobreza, da exclusão ou da desigualdade no Brasil.

A partir do entendimento de que a emancipação cívica e a conquista da cidadania ativa é um processo de destruição dos mecanismos de tutela e ampliação do universo cultural e educacional. É necessário buscar e dar visibilidade aos caminhos que dão voz e vez a um maior número de pessoas, favorecendo a criação de novos espaços públicos. Qualquer programa de enfrentamento da pobreza é parte desse processo e precisa ser avaliado nesse sentido. 
Finalmente, podemos dizer que o espaço local entendido como o motor de arranque do processo de enfrentamento da pobreza precisa ser privilegiado. A construção de múltiplas formas de identificação e de avaliação de práticas e de soluções eficazes - por instâncias independentes - pode prestar um serviço importante à sociedade. No Brasil, não há uma tradição de efetiva avaliação de políticas públicas da parte de organismos governamentais. Além do que, a produção de dados sobre a heterogeneidade da pobreza, a desigualdade, como também sobre os resultados e impactos de ações - sejam estas positivas ou negativas é essencial para evitar que o fenômeno perca seus contornos sóciopolíticos e gere uma individualização tutelada, transformando a pobreza em "pobre". A criação de indicadores de avaliação e de uma base independente de dados estatísticos socialmente adequados é de extrema importância para a mudança da nossa realidade.Vale lembrar que falta de renda não é sinônimo de pobreza, mas é um dado importante a ser considerado, chamando a atenção para as conseqüências das relações socioeconômicas constitutivas do quotidiano. Porém, ações nesta área precisam reconhecer a importância da emancipação política e do engajamento de atores locais na discussão do desenvolvimento do "lugar". Essas ações precisam se iniciar a partir de bases sólidas, simples e participativas, permitindo resultados concretos e sustentáveis. Nesse sentido as experiências demonstram que integração entre outros atores e setores, quando acontecem, são normalmente resultados de um processo gradual de aproveitamento de oportunidades, de aprendizagem e de luta, abrindo possibilidades de escolhas seguindo o cronograma dos atores e acontecimentos.

\section{Implicações para a administração cotidiana}

Os resultados das experiências analisadas e das oficinas de discussão e debate deixaram muito claro o quanto à construção e reprodução da pobreza e da desigualdade se faz presente no cotidiano, nas pequenas práticas públicas que caracterizam os lugares e os horizontes do dia a dia, nas muitas barreiras sutis e não sutis que afastam este ou aquele grupo do acesso a um serviço de qualidade e a uma dignidade básica.

Durante muito tempo, a discussão sobre reforma administrativa focalizava -seja na sua vertente burocrática, seja na vertente gerencial - o eixo dos serviços. A suposição de que é melhor ter mais serviços, mesmo que os mecanismos de acesso a estes sejam pouco 
transparentes, é uma característica constante em muitos programas de desenvolvimento. Mas, o resultado destes programas é que muitas vezes, os mais bem situados na pirâmide social tiram mais vantagens dos serviços oferecidos.Ou seja, uma estratégia baseada na mera expansão dos serviços corre o risco de reproduzir os padrões de exclusão existente.

O que parece ser necessário é reconhecer as possibilidades de ação de uma gestão pública na perspectiva da cidadania e dos direitos (Spink, 2000).Isto é, uma gestão pública preocupada com o impacto dos serviços e das ações públicas no cotidiano do exercício da cidadania entendido no seu sentido mais amplo. Onde os serviços serão julgados eficazes não porque são mais rápidos ou mais baratos, ou ainda porque produzem mais ação, mas por gerarem conseqüências tangíveis, aceitáveis e claras para as condições e a prática da cidadania, para a redução da desigualdade e da pobreza; tanto para quem recebe quanto para quem fornece e para quem participa da comunidade mais ampla em que as ações ocorrem. O foco, portanto é com o lugar, com as barreiras, os bloqueios e com as maneiras em que milhares de pequenas ações e possibilidades de ação são interpretadas e reinterpretadas (Lipsky 1980, Spink 2003).

O desafio não é de criar ou conceituar esta nova perspectiva, mas ao contrário, de reconhecer o que já existe e dar voz às suas idéias e práticas.

\section{Bibliografia}

Camarotti, Ilka \& Spink, Peter (2000a). Parcerias e Pobreza: soluções locais na construção de relações sócio-econômicas. Rio de Janeiro: Editora da Fundação Getulio Vargas.

Camarotti, Ilka \& Spink, Peter (2000b). Parcerias e Pobreza: soluções locais na implementação de políticas sociais. Rio de Janeiro: Editora da Fundação Getulio Vargas.

Federação de Órgãos para Assistência Social e Educacional (FASE) (2003). Estudo sobre indicadores de desenvolvimento humano no projeto Brasil 2000 - novos marcos para as relações raciais. Rio de Janeiro.

Freire, Paulo (2001). Ação Cultural para a Liberdade.São Paulo: Paz e Terra. 
Lipsky, Michael (1980). Street-Level Bureaucracy: dilemmas of the individual in public services. New York: Russell Sage Foundation.

Spink, Peter (2000). "The rights based approach to local public management: experiences from Brazil". Revista de Administração de Empresas. 40, 3, 45-65.

Spink, Peter (2003). "Poverty and Place". In Carr, Stuart C. \& Sloan, Tod. Poverty and Psychology : from global perspective to local practice. New York: Kluwer Academic/Plenum Publishers.

Artigo recebido em 20/10/2004. Aprovado em 20/03/2005. 